\title{
Modeling the effects of ICT on environmental sustainability: revisiting a system dynamics model developed for the european commission
}

\author{
Ahmadi Achachlouei, Mohammad ; Hilty, Lorenz M
}

\begin{abstract}
This chapter revisits a System Dynamics model developed in 2002 with the aim of exploring the future impacts of Information and Communication Technology (ICT) on environmental sustainability in the EU, which then consisted of 15 countries. The time horizon of the study was 20 years (2000-2020). We analyze the results in light of empirical data that is now available for 2000-2012. None of the three scenarios that were developed by experts to specify the external factors needed to run the model were realistic from today's point of view. If the model is re-run with more realistic input data for the first half of the simulation period, however, the main results regarding the impact of ICT remain qualitatively the same; they seem to be relatively robust implications of the causal system structure, as it is represented in the model. Overall, the impacts of ICT for mitigating greenhouse gas emissions and other environmental burdens for 2020 tend to be slightly stronger if the simulation is based on the empirical data now available.
\end{abstract}

DOI: https://doi.org/10.1007/978-3-319-09228-7_27

Posted at the Zurich Open Repository and Archive, University of Zurich ZORA URL: https://doi.org/10.5167/uzh-110002

Book Section

Accepted Version

Originally published at:

Ahmadi Achachlouei, Mohammad; Hilty, Lorenz M (2015). Modeling the effects of ICT on environmental sustainability: revisiting a system dynamics model developed for the european commission. In: Hilty, Lorenz; Aebischer, Bernard. ICT Innovations for Sustainability. Cham: Springer, 449-474.

DOI: https://doi.org/10.1007/978-3-319-09228-7_27 


\title{
Modeling the Effects of ICT on Environmental Sustainability: Revisiting a System Dynamics Model Developed for the European Commission
}

\author{
Mohammad Ahmadi Achachlouei ${ }^{1,2,3}$, Lorenz M. Hilty ${ }^{2,3,4}$ \\ ${ }^{1}$ Division of Environmental Strategies Research fms, KTH Royal Institute of Technology, \\ Stockholm, Sweden \\ Mohammad.achachlouei@abe.kth.se \\ ${ }^{2}$ Centre for Sustainable Communications CESC, KTH Royal Institute of Technology, \\ Stockholm, Sweden \\ ${ }^{3}$ Empa, Swiss Federal Laboratories for Materials Science and Technology, \\ St. Gallen, Switzerland \\ ${ }^{4}$ Department of Informatics, University of Zurich, Zurich, Switzerland \\ hilty@ifi.uzh.ch
}

\begin{abstract}
This chapter revisits a System Dynamics model developed in 2002 with the aim of exploring the future impacts of Information and Communication Technology (ICT) on environmental sustainability in the EU, which then consisted of 15 countries. The time horizon of the study was 20 years (20002020). We analyze the results in light of empirical data that is now available for 2000-2012. None of the three scenarios that were developed by experts to specify the external factors needed to run the model were realistic from today's point of view. If the model is re-run with more realistic input data for the first half of the simulation period, however, the main results regarding the impact of ICT remain qualitatively the same; they seem to be relatively robust implications of the causal system structure, as it is represented in the model. Overall, the impacts of ICT for mitigating greenhouse gas emissions and other environmental burdens for 2020 tend to be slightly stronger if the simulation is based on the empirical data now available.
\end{abstract}

Keywords: Information and Communication Technology; Environmental Impact; Sustainable Development; Information Society; Socioeconomic Modeling and Simulation; System Dynamics; Prospective Technology Assessment.

\section{Introduction}

In 2002, the European Commission's Institute for Prospective Technological Studies (IPTS) commissioned a study to explore the current and future effects of ICT to a consortium led by the Institute for Futures Studies and Technology Assessment (IZT), Berlin, Germany. The aim of the study was to estimate positive and negative effects

This Accepted Author Manuscript is copyrighted by Springer. The final publication will be available via http://link.springer.com/bookseries/11156 by end of August 2014. Suggested citation: Ahmadi Achachlouei, M., Hilty, L.M.: Modeling the Effects of ICT on Environmental Sustainability: Revisiting a System Dynamics Model Developed for the European Commission. In: Hilty, L.M., Aebischer, B. (eds.) ICT Innovations for Sustainability. Advances in Intelligent Systems and Computing 310. Springer International Publishing (2014, in press) 
of the ongoing "informatization" of society on environmental indicators with a time horizon of 20 years. The method applied was to develop future scenarios, build a model based on the System Dynamics approach, validate the model, and use it to run quantitative simulations of the scenarios. The results were published in 2003 and 2004 in five interim reports [1-5], one final report [6], and several articles [7-10]. This study was, to our knowledge, the first attempt to simulate the future positive and negative environmental impacts of ICT at a macroeconomic level.

In this paper, we will revisit the results and the methodology of the study - in the following called "the IPTS study" - in light of the developments observed during the past decade. We will critically examine the simulated scenarios from today's point of view and investigate how the predictions made by the study match current empirical data.

A background report published by KTH serves as supplementary material to this chapter [27]. We will refer to it whenever the data to be presented would exceed the space provided for this chapter.

\section{Development and Application of the Simulation Model}

\subsection{Context of Model Development and Application}

The aim of the model was to estimate the following environmental indicators (which relate to those reported to the Spring European Council in March of each year) for the year 2020 and to isolate the effect of ICT on them:

- Total freight transport

- Total passenger transport

- Modal split (private car transport vs. public transport)

- Total energy consumption

- The share of electricity generation from renewable sources

- Greenhouse gas emissions

- Municipal solid waste not recycled

The idea of the model was to enable simulation experiments in which one could "switch on" and "switch off" ICT trends such as telework, mobile work, virtual meetings, Intelligent Transport Systems (ITSs), intelligent heating, etc., and observe how this affects the indicators. The model as such can be viewed as an instrument of integrated impact assessment [11]. The project consortium consisted of the following organizations:

- Institute for Futures Studies and Technology Assessment (IZT), Germany,

- Forum for the Future (FFF), Great Britain,

- Swiss Federal Laboratories for Materials Testing and Research (Empa), Switzerland,

- International Institute for Industrial Environmental Economics (IIIEE) at Lund University, Sweden. 
IZT was responsible for the overall coordination and data collection, FFF for scenario development, Empa for model development and simulation, and IIIEE for the policy recommendations derived from the results.

\subsection{Basic Terminology and Method}

The terminology and method used in the original study are described in detail in Chapter 2 of the fourth interim report [4]. We will briefly recapitulate the most basic concepts: model, simulation, scenario, and System Dynamics.

We define a model as a system S' that an observer uses in the place of a system $\mathrm{S}$ in order to answer questions that interest him/her about $\mathrm{S}$. The method of simulation (as opposed to the analytical use of models) is a specific way of using $S$ ' to generate answers, namely experimentation. In a simulation experiment, the model is exposed to experimental conditions, represented by the simulation input data, and shows an observable reaction by producing simulation output data. A simulation model is a model specifically designed to be used for simulation.

The simulation experiment makes a prediction of the form "if...then," where the "if" part is represented by the input data used to feed some of the model variables and the "then" part by the output data generated by calculating other (dependent) model variables. It is the conditional nature that makes a prediction different from a forecast, which calculates future values of all model variables based on their initial values only [12]. Strictly speaking, a forecast is a special case of a prediction.

The simulation experiments were based on scenarios of the type called "What-if" scenarios in the typology of Börjeson et al. [41]. These scenarios were developed in expert workshops and described in natural language. The simulation input data were derived from the "if"-part of the scenario. This included, for example, the future development of the price of oil and other quantities considered external factors and thus input variables to the model. The model then simulated the development under the assumptions made in the scenarios. Because the simulation experiments only differed by the input data derived from the scenarios, these data vectors were called "scenarios" in the project.

For each scenario, three sub-scenarios were created which expressed best-case, worst-case, and mean assumptions about model parameters that were specified with a range of uncertainty. The "mean" sub-scenarios simply used the arithmetic mean of the best- and worst-case values of each (input) parameter.

System Dynamics is a specific modeling approach characterized by giving the model builder the possibility of expressing the structure of the system as a network of causal links, or more precisely, stocks that are interlinked by material flow, while the flow rates are controlled by information about the stocks. The models are represented mathematically as ordinary differential equations and solved numerically. 


\section{Future Scenarios Simulated in $\mathbf{2 0 0 3}$}

The task of the original study was to make a prediction about the future effect of ICT on environmental sustainability. When building the System Dynamics model, it soon became clear that this prediction would depend on conditions that were external to the model, called "external factors," in particular: the development of the general economic activity level (usually represented by the Gross Domestic Product, GDP), the labor market, energy prices, the climate for innovation, the general attitude of the population toward ICT and toward environmental issues, spatial dispersion, and the speed of some technological developments.

Given the fundamental difficulty to forecast these factors over 20 years, the project team applied a scenario approach to deal with the uncertainty. In expert and stakeholder workshops, three possible futures were developed in the form of scenarios, each of them representing a development that was internally consistent and plausible according to the participants' assessment. Brief descriptions of the original scenarios are repeated here [4]:

- Scenario A, called "Technocracy," was characterized by strong economic growth, leading to an increase in the workforce which is also reflected in an increase in desk workers due to the service-based nature of the economy. Strong growth also leads to a significant increase in the total number of households and buildings due to increased economic activity. Collusion between government and business in determining the framework for business activity is dominated by large companies, which is reflected in a fall in the number of SMEs.

- Scenario B, called "Government first," was characterized by weak economic growth which is reflected in the lack of growth in the number of households, buildings, and desk workers. The total labor force decreases due to stagnating economic growth and the flight of industry from Europe. The settlement pattern becomes more dispersed due to the development and high take-up of environmental and social applications of technology, for example ITSs, smart homes, and virtual conferencing. This also leads to an increase in the percentage of SMEs.

- Scenario C, called "Stakeholder democracy," was characterized by steady economic growth, leading to an increase in the number of households and desk workers and the total labor force. A reduction in the levels of inequality between the developed and developing worlds and the expansion of the EU to 35 Member States reduce immigration to Europe and, as a result, the expected rise in population does not materialize. The settlement pattern becomes more dispersed due to business investment in applications that can improve virtual conferencing and smart home technologies.

These scenarios were then operationalized by mapping them to values of 14 external model variables, mostly in the form of parameters that specified the speed of an expected change of the given variable either in terms of an annual growth rate or in terms of a half-life value. The upper part of Figure 1 shows the role of the scenarios $\mathrm{A}, \mathrm{B}$, and $\mathrm{C}$ in the original study. 
The model was then used to make predictions of the form: "If the system under study ${ }^{1}$ develops according to Scenario A, then ICT will have the following effect on environmental indicators in 2020: ..." Most interesting, however, were ICT effects that turned out to be robust with regard to the scenario chosen, i.e., that could be observed across all scenarios. One example was the result that ICT would (despite telework, teleshopping and virtual meetings, virtual goods and ITSs) not slow down the growth of overall passenger transport due to rebound effects (e.g., time-efficient transport stimulates demand), but instead shift the modal split back to more public transport, inhibiting the growth of private car transport. This was explained by the increasing opportunities for mobile work that created a comparative advantage for public transport (time utilization effect). Other output variables depended on the scenario chosen and therefore had to be interpreted with high uncertainty. Examples of output variables on which ICT had a stimulating or inhibiting (if not reducing) effect depending on the scenario chosen include:

- ICT had an inhibiting effect on total freight transport only in Scenario A (under best-case assumptions) and in Scenario C (except for worst-case assumptions). In all other cases, ICT increased freight transport by creating efficiency gains that were compensated for by rebound effects of $100 \%$ or more [4, p. 82].

- ICT had a much more inhibiting effect on total energy consumption in Scenarios A and C than in B [4, p. 57]. This seems surprising because B was the scenario assuming the highest take-up of environmental applications of technologies. However, $\mathrm{B}$ is also the one with the weakest economic growth, leading to a stabilization of energy consumption (which increased further in A and C), which in turn left less space for energy-saving ICT applications. In other words, the more energy is used, the higher is the savings potential by efficiency measures, including ICT. Overall, $\mathrm{B}$ was the scenario with the most advantageous environmental indicators [4, p. 56].

Today, a decade after the three scenarios were defined, it seems reasonable to conduct an ex-post validation of the simulation study. In the following, we will describe how we not only tested the validity of the original scenarios (the "if" part of the simulation study), but also developed a new one which is exactly calibrated with the empirical data that is now available about roughly the first decade of the time window simulated. This "Scenario D" will then be used to renew the predictions of the model for the second decade of the simulation period in order to restate the "then" part of the simulation result with reduced uncertainty (see also Figure 1).

1 In this case, the system under study was defined as the sum of the national economies of EU15. 
Expert assessments or statistical data

Scenarios and derived model input data

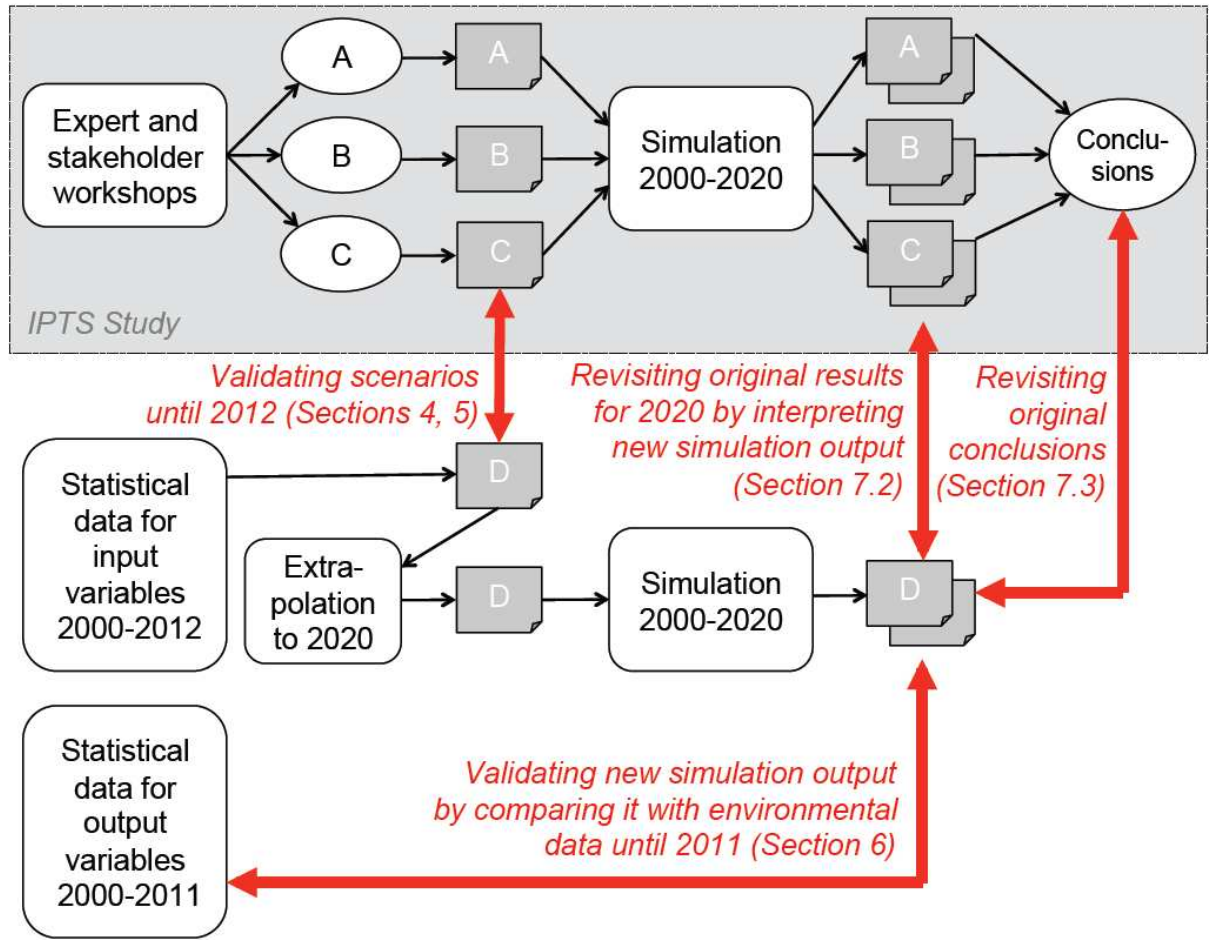

Fig. 1. Data flow in the original study (grey box) and in the current study

\section{Comparing Simulation Assumptions with Empirical Data}

This section addresses the following research question (RQ), based on a search in currently available data:

RQ1: Which of the three scenarios comes closest to reality?

To answer this question, we checked parameters such as GDP growth and other assumptions underlying the scenarios against the reality of the past 12 years (20002012). None of the three scenarios dominantly represents reality during this period. Scenario A and B come closest to the real-world data in seven cases each, and Scenario $\mathrm{C}$ in five cases (as shown in the last column of Table 1).

To answer RQ1, Table 1 lists, in the left-hand columns, all model inputs in the IPTS study (taken from Table 4-3 in the 4th interim report [4]), of which 14 were used to differentiate between the scenarios. These are economic variables (M2, M4, M15, M16, E400, E17), demographic variables (M7, M9), variables regarding the 
efficiency of electricity supply and use in general (E13, E20), and variables expressing how people use ICT (U400, T400, U201). ${ }^{2}$ In addition, W32 describes progress in recycling technology for Municipal Solid Waste (MSW) in general. Each scenario is formally represented as a vector of these 14 variables. The task was to find out which vector is closest to reality, given the observed development in EU15 from 2000 to 2012 (or at least for the years for which data are available).

Table 1 presents the real-world statistical data for the model input described in Table 4-3 in [4]. The Compound Annual Growth Rate (CAGR) formula was used to calculate the annual growth rates using empirical data for beginning and ending years (Table 1):

$$
C A G R=\left(\frac{\text { Ending value }}{\text { Beginning value }}\right)^{\left(\frac{1}{\# \text { of years }}\right)}-1
$$

Detailed calculations associated with Table 1 can be found in a report that provides supplementary information to this chapter [27]. A discussion of the results shown in Table 1 is provided below.

GDP Annual Growth Rate (M2). For M2, Scenario B was closest to the empirical data. However, assumptions for this parameter were overestimated in all three scenarios. The closest assumption for the expected average annual growth rate of GDP, i.e., $2.12 \% / a$ (in Scenario B) was still about twice as much as the observed GDP annual growth rate, i.e., $1.11 \%$ /a for $2000-2012$.

One reason for the overestimation of M2 might be that the IPTS study could not anticipate the 2008 financial crisis and the associated economic slowdown in 2009 . The annual growth rate for $2000-2008$, i.e., $1.88 \%$ a, is clearly higher than the rate for 2000-2012 [16], but still lower than Scenario B. Perhaps the general political climate for growth was more positive or optimistic when the IPTS study was conducted.

Labor Demand Annual Growth Rate (M4). For M4, Scenario A was closest to the empirical data. The observed annual growth rate for total employment in EU-15 over $2000-2012$, i.e., $0.67 \%$ a, is higher than the highest value $0.42 \%$ a (assumed for Scenario A). This assumption was clearly underestimated.

Population Annual Growth Rate (M7). For M7, Scenarios A and B were closest to the empirical data, although the observed growth rate $(0.46 \% / \mathrm{a})$ was almost three times higher than the rate assumed for these scenarios. (Scenario C assumed zero growth because of the assumed reduced immigration.) M7 was clearly underestimated in the IPTS study.

2 We retained the original identifiers for the variables (such as "M2") for those readers who wish to consult [4] for details. 
Number of Households Annual Growth Rate (M9). For M9, Scenario A was closest to the empirical data. The observed rate is $1.51 \% /$ a for $2005-2012$. Here, we should assess the logic behind the assumption made for M9. The IPTS study assumed M9 to be roughly equal to population growth in scenario $\mathrm{B}$, higher in $\mathrm{C}$, and much higher in A (due to GDP growth that allows for smaller households). The observed rate for population growth for 2005-2012 is $0.38 \%$ /a [19]. Note that our observation for this parameter is incomplete, and it does not include data for 2000-2004.

Number of SMEs Annual Growth Rate (M15). For M15, Scenario B was closest to the empirical data. Based on the scenario descriptions, the IPTS study assumed this growth rate to be half, double, or equal to M4, the labor demand annual growth rate. Our observation for M15 (0.78\%/a for 2005-2012) was almost twice as high as the observed data for M4 for the same period (0.34\% for 2005-2012) [13], so Scenario B was chosen as the closest.

Office Work Demand Annual Growth Rate (M16). For M16, Scenario A was closest to the empirical data. Instead of looking at absolute values of assumptions, we assessed the logic behind the assumption. The IPTS study had assumed that in Scenarios $\mathrm{A}$ and $\mathrm{C}$, the demand for office work would change in parallel to general labor demand, and that in Scenario B, the demand would be stable (despite negative growth of general labor demand) due to structural change. We collected empirical data on employment growth in knowledge-intensive high-technology services, knowledgeintensive market services, and ICT services, which were used as proxy for office work demand.

Fossil Energy Price Change Rate (E400). For E400, Scenario B was closest to the empirical data. The IPTS study used the world oil price as the proxy for E400. However, since oil prices increased considerably $(8.8 \% / \mathrm{a})$ over the past years at the global level, "while natural gas and other energy prices have seen differing developments in each world region" [30], we chose a different proxy for E400: automotive gas oil (diesel fuel) with the CAGR of $2.8 \%$ /a, which was closer to the forecast rate in Scenario $\mathrm{B}$, but much higher than the rates in other scenarios $(0.35 \% / \mathrm{a}$ for $\mathrm{A}$ and $\mathrm{C}$ and $3 \% / \mathrm{a}$ for B; the IPTS study assumed that environmental costs are internalized in scenario $\mathrm{B}$, whereas scenarios $\mathrm{A}$ and $\mathrm{C}$ assumed a strong increase of real energy prices.)

Shift to Energy-Efficient ICT Half-life (U400). For U400, given the data collected on energy efficiency of data centers, microprocessors, servers, and standby mode (presented below), we decided to choose the optimistic estimation, i.e., Scenario $\mathrm{C}$ in this case, as the scenario closest to the actual development. To make it simpler, the IPTS study used a half-life parameter (15 years in scenarios A and B and 7.5 years in scenario C) for all of the energy-saving potentials-i.e., $40 \%$ for servers, $12.1 \%$ for client standby consumption, $3 \%$ for client off-mode consumption, and $55 \%$ for the CRT-to-LCD shift. The IPTS study made the claim that all of these potentials were 
approached at the same speed as a consequence of technology improvement in ICT equipment. To compare (and falsify) this assumption with the real-world data, we chose the energy-saving potential for servers (40\%). How fast has this potential developed since 2000? A study on server and data center energy efficiency (US-EPA 2007) identified key components on the server side: microprocessors, servers, storage devices, and site infrastructure systems. The energy efficiency of microprocessors and servers (performance per watt) has increased at an annual growth rate of $50 \%-60 \%$ over 2006-2013 [32,33]. The efficiency of site infrastructure systems, which is measured in Power Usage Effectiveness (PUE) [34], has also been improved in recent years with an average PUE factor of 2.5 in 2007 to 1.65 in 2013 [35], i.e., about 7.8\% improvement per year. In terms of energy efficiency of Internet data flows, the energy intensity of the Internet has decreased by $30 \%$ per year on average since 2000 [46][36]. These observations show a faster development of the assumed potential for servers than the half-life of 15 or 7.5 years assumed in the IPTS study. It is obvious that all 3 scenarios greatly underestimated efficiency potentials and speed. Scenario C in the IPTS study had assumed that an LCA/eco-labeling system would be introduced for ICT. Some labels for hardware that have been introduced might have had an influence on the more rapid shift to energy-efficient ICT. (In the other scenarios, no nonfiscal policies promoting a shift toward more rational energy use in the ICT area were mentioned.)

ICT-Induced Spatial Settlement Dispersion (T400). For T400, Scenarios B and C were closest to the empirical data. We collected empirical data on average commuting distance as a proxy for T400. The observed data, 20\% growth over the period 20002010 in Finland, comes closest to $25 \%$ within a period of 20 years in Scenarios B and C. These scenarios in the IPTS study had assumed that the settlement pattern would become more dispersed due to the diffusion of ITSs, video-conferencing and intelligent home technology. However, the source of the empirical proxy data used here (Finnish Environment Institute) mentioned three factors as the main reason for the growth in average commuting distance: expansion of commuting areas, increasing levels of commuting between urban regions, and specialization of jobs.

D\&T Electricity Use Efficiency Potential (E12) and Half-life (E13). For the combination of E12 and E13, Scenarios A and C were closest to the empirical data. We used proxy data from EU-27, i.e., a roughly $8 \%$ increase in energy efficiency over the period 2000-2009. This directs us to the half-life of 30 years, which is a higher value than the assumptions of Scenarios A and C (15 years) and Scenario B (7.5 years). This means that the assumed D\&T electricity use efficiency potential E12 $(50 \%)$ has not been exploited as rapidly as assumed in the scenarios. (The high speed in Scenario $\mathrm{B}$ had been justified in the IPTS study assuming governmental regulations.)

D\&T Electricity Price Annual Growth Rate (E17). For E17, Scenario B was closest to the empirical data. The observed annual growth rate of the domestic electricity price $(3.9 \% / \mathrm{a}$, calculated from Eurostat [20]) deviates strongly from the assumed 
values for Scenarios A and C (-0.45\%) and Scenario B (0\%)—The IPTS study had based its calculations on European Commission data [42].

Electricity Supply Efficiency Potential (E19) and Half-life (E20). For the combination of E19 and E20, Scenarios A and C were closest to the empirical data. The observed data (7\% increase in efficiency over the period 2000-2010) is more consistent with Scenario A and C.

Average Useful Life of ICT Change Rate (U201). For U201, Scenarios A and C were closest to the empirical data. The empirical data (about 7.3\%/a decrease in average useful life of personal computers as a proxy) were closer to the rate of $8 \% / \mathrm{a}$ decrease in Scenarios A and C.

MSW Recycling Potential (W31) and Half-life (W32). For the combination of W31 and W32, Scenario B was closest to the empirical data. The observed recycling rate for the year 2011 in EU-15 was 28\% of the MSW. Using this figure, we derived the half-life value of 10 years. This is closer to the speed assumed in Scenario B, where the half-life value of 8 years would result in a recycling rate of $32.6 \%$ in 2011 to realize the potential W31 (53\%) - compared to the half-life of 20 years in Scenarios A and $\mathrm{C}$ which would calculate $17 \%$ for recycling rate in 2011 . (The IPTS study assumed a rough estimate for the potential W31, and the half-life values W32 were a compromise between the project team's and the workshop participants' estimates. Scenario B was assumed to exploit the potential more quickly because of government regulations.)

Elasticity Parameters. The elasticity parameters G50, E220, E15, T97, and T305 were not used in the original study to differentiate between Scenarios A, B, and C. However, they were now re-calibrated based on empirical data (see references provided in the column "Empirical data for EU15") for the Scenario D simulation.

Table 1. Comparing simulation assumptions (taken from Table 4 in the $4^{\text {th }}$ interim report of the IPTS study [4]) with empirical data. We retained the original identifiers for the variables (such as "M2") for those readers who wish to consult [4] for details.

\begin{tabular}{|l|l|c|c|c|c|l|}
\hline No & $\begin{array}{l}\text { External } \\
\text { variable }\end{array}$ & \multicolumn{2}{|c|}{$\begin{array}{c}\text { Scenario assumptions used as } \\
\text { simulation input } \\
\mathbf{2 0 0 0 - 2 0 2 0}\end{array}$} & $\begin{array}{c}\text { Empirical data for EU15 } \\
\mathbf{2 0 0 0 - 2 0 1 2}\end{array}$ & $\begin{array}{l}\text { Scenario } \\
\text { closest to } \\
\text { reality }\end{array}$ \\
\cline { 2 - 5 } & $\begin{array}{c}\text { Scenario } \\
\mathbf{A}\end{array}$ & $\begin{array}{c}\text { Scenario } \\
\text { B }\end{array}$ & $\begin{array}{c}\text { Scenario } \\
\text { C }\end{array}$ & \\
\hline M2 & $\begin{array}{l}\text { GDP Annual } \\
\text { Growth Rate }\end{array}$ & $2.56 \%$ & $2.12 \%$ & $2.3 \%$ & $\begin{array}{c}1.11 \% \\
\text { increase over 2000- } \\
\text { 2012) }[16]\end{array}$ & B \\
\hline
\end{tabular}


M. Ahmadi Achachlouei and L.M. Hilty

\begin{tabular}{|c|c|c|c|c|c|c|}
\hline M4 & $\begin{array}{l}\text { Labor Demand } \\
\text { Annual Growth } \\
\text { Rate }\end{array}$ & $0.42 \%$ & $-0.15 \%$ & $0.27 \%$ & $\begin{array}{c}0.67 \% \\
(8.3 \% \text { increase over } 2000- \\
\text { 2012) [17] }\end{array}$ & A \\
\hline M7 & $\begin{array}{l}\text { Population Annu- } \\
\text { al Growth Rate }\end{array}$ & $0.16 \%$ & $0.16 \%$ & $0 \%$ & $\begin{array}{c}0.46 \% \\
(5.7 \% \text { increase over } 2000- \\
\text { 2012) [18] }\end{array}$ & A \& B \\
\hline M9 & $\begin{array}{l}\text { Number of } \\
\text { Households An- } \\
\text { nual Growth Rate }\end{array}$ & $0.85 \%$ & $0.18 \%$ & $0.7 \%$ & $\begin{array}{c}1.51 \% \text { for } 2005-12 \\
(11.1 \% \text { increase over } 2005- \\
\text { 2012) [19] }\end{array}$ & A \\
\hline M15 & $\begin{array}{l}\text { Number of SMEs } \\
\text { Annual Growth } \\
\text { Rate }\end{array}$ & $0.21 \%$ & $0.84 \%$ & $0.42 \%$ & $\begin{array}{c}0.78 \% \text { for } 2005-12 \\
(5.6 \% \text { increase over } 2005- \\
\text { 2012) [13] }\end{array}$ & $\mathrm{B}^{3}$ \\
\hline M16 & $\begin{array}{l}\text { Office Work } \\
\text { Demand Annual } \\
\text { Growth Rate }\end{array}$ & $0.42 \%$ & $0.0 \%$ & $0.27 \%$ & $\begin{array}{c}1.28 \% \\
\text { for } 2008-2011 \text { [19] }\end{array}$ & $A^{4}$ \\
\hline E400 & $\begin{array}{l}\text { Fossil Energy } \\
\text { Price Annual } \\
\text { Change Rate }\end{array}$ & $0.35 \%$ & $3 \%$ & $0.35 \%$ & $\begin{array}{c}2.8 \% \\
\text { Automotive gas oil price as } \\
\text { proxy }\end{array}$ & $\mathrm{B}^{5}$ \\
\hline U400 & $\begin{array}{l}\text { Shift to Energy- } \\
\text { Efficient ICT } \\
\text { Half-life }\end{array}$ & $15 \mathrm{a}$ & $15 \mathrm{a}$ & $7.5 \mathrm{a}$ & $\begin{array}{c}\sim 7.5 \mathrm{a} \\
{[32,33,34,35,36]}\end{array}$ & $\mathrm{C}$ \\
\hline $\mathrm{T} 400$ & $\begin{array}{l}\text { ICT-Induced } \\
\text { Spatial Settlement } \\
\text { Dispersion }\end{array}$ & 0 & $+25 \%$ & $+25 \%$ & $\begin{array}{l}20 \% \text { increase in average } \\
\text { commuting distance over the } \\
\text { period } 2000-2010 \text { in Finland } \\
\text { as proxy [22] }\end{array}$ & B \& $\mathrm{C}^{6}$ \\
\hline E12 & $\begin{array}{l}\text { D\&T Electricity } \\
\text { Use Efficiency } \\
\text { Potential }\end{array}$ & \multicolumn{3}{|c|}{$+50 \%$} & \multirow{2}{*}{$\begin{array}{c}\sim 30 \mathrm{a} \\
(7.9 \% \text { increase in efficiency } \\
\text { over } 9 \text { years } 2000-2009 \text { in } \\
\text { EU-27) }[15]\end{array}$} & \multirow[t]{2}{*}{$A \& C$} \\
\hline E13 & $\begin{array}{l}\text { D\&T Electricity } \\
\text { Use Efficiency } \\
\text { Half-life }\end{array}$ & $15 \mathrm{a}$ & $7.5 \mathrm{a}$ & $15 \mathrm{a}$ & & \\
\hline E17 & $\begin{array}{l}\text { D\&T Electricity } \\
\text { Price Annual } \\
\text { Growth Rate }\end{array}$ & $-0.45 \%$ & $0 \%$ & $-0.45 \%$ & $\begin{array}{c}3.9 \% \\
(35 \% \text { increase over } 2005- \\
\text { 2013) [20] }\end{array}$ & B \\
\hline E19 & $\begin{array}{l}\text { Electricity Supply } \\
\text { Efficiency Poten- } \\
\text { tial }\end{array}$ & \multicolumn{3}{|c|}{$+25 \%$} & \multirow{2}{*}{$\begin{array}{c}\sim 20 \mathrm{a} \\
(7.1 \% \text { increase in efficiency } \\
\text { over 10 years } 2000-2010) \\
{[14]}\end{array}$} & \multirow[t]{2}{*}{$A \& C$} \\
\hline E20 & $\begin{array}{l}\text { Electricity Supply } \\
\text { Efficiency Half- } \\
\text { life }\end{array}$ & $20 \mathrm{a}$ & $10 \mathrm{a}$ & $20 \mathrm{a}$ & & \\
\hline
\end{tabular}

3 Employment growth rate (M4) for 2005-2012 in EU15 was 0.34\%/a

4 Employment growth rate (M4) for 2008-2011 in EU15 was 0.69\%/a. Note 2: The empirical data collected for M16 is a proxy.

5 The empirical data here represents automotive gas oil in the EU. We did not use the world oil price, the CAGR of which was $8.8 \%$ over 2000-2012 [23].

6 It was unclear whether the increase was ICT-induced or not. 


\begin{tabular}{|c|c|c|c|c|c|c|}
\hline U201 & $\begin{array}{l}\text { Average Useful } \\
\text { Life of ICT An- } \\
\text { nual Change Rate }\end{array}$ & $-8.0 \%$ & $0 \%$ & $-8.0 \%$ & $\begin{array}{c}-7.3 \% \\
\text { over } 8 \text { years } 2000-2008 \\
{[25,26]}\end{array}$ & $A \& C$ \\
\hline W31 & $\begin{array}{l}\text { MSW Recycling } \\
\text { Potential }\end{array}$ & \multicolumn{3}{|c|}{$53 \%$} & \multirow{2}{*}{$\begin{array}{c}\sim 10 \mathrm{a} \\
(28 \% \text { recycling rate in } 2011) \\
{[28]}\end{array}$} & \multirow[t]{2}{*}{ B } \\
\hline W32 & $\begin{array}{l}\text { MSW Recycling } \\
\text { Half-life }\end{array}$ & $20 \mathrm{a}$ & $8 \mathrm{a}$ & $20 \mathrm{a}$ & & \\
\hline G50 & $\begin{array}{l}\text { Industrial Materi- } \\
\text { als Price Elasticity }\end{array}$ & \multicolumn{3}{|c|}{$-0.5(5 a)$} & $-0.2[37]$ & * \\
\hline E220 & $\begin{array}{l}\text { Industrial Energy } \\
\text { Price Elasticity }\end{array}$ & \multicolumn{3}{|c|}{$\begin{array}{l}\qquad-0.5(5 \text { a) } \\
\text { Assumed to be equal to G50 }\end{array}$} & $\begin{array}{c}-0.2 \\
\text { Assumed to be equal to G50 }\end{array}$ & $*$ \\
\hline E15 & $\begin{array}{l}\text { D\&T Electricity } \\
\text { Price Elasticity }\end{array}$ & \multicolumn{3}{|c|}{$-0.5(5 a)$} & $-0.2[40]$ & * \\
\hline T97 & $\begin{array}{l}\text { Air Transport } \\
\text { Price Elasticity }\end{array}$ & \multicolumn{3}{|c|}{$-1.5(5 \mathrm{a})$} & $-0.8[38]$ & $*$ \\
\hline T305 & $\begin{array}{l}\text { Freight Transport } \\
\text { Energy Price } \\
\text { Elasticity }\end{array}$ & \multicolumn{3}{|c|}{$-1.5(5 a)$} & $-0.175[39]$ & $*$ \\
\hline
\end{tabular}

* The elasticity parameters G50, E220, E15, T97, and T305 were not used in the comparison since they did not vary among old scenarios A, B, and C. However, these parameters were included in this table because their updated (empirical) values were used in the new scenario D (see Section 5).

Note: Short description of the variables: M2: Expected average annual growth rate of Gross Domestic Product (GDP). M4: Expected average annual growth rate of labor demand. M7: Expected average annual growth rate of the population. M9: Expected average annual growth of the total number of households. M15: Expected annual growth of the total number of small and medium-sized enterprises. M16: Expected average annual growth rate of the demand for office work. E400: Average annual change rate of real energy prices for fossil fuels. U400: How many years after beginning of simulation will half of the energysaving potentials for making ICT more energy-efficient (reducing standby and off-mode consumption, power management for servers) be exploited under the assumption of constant real energy prices? T400: Expected impact of ICT diffusion (e.g., ITSs, virtual conferencing technology, etc.) on settlement dispersion, expressed as the increase in average transport distance of goods and people within a period of 20 years. E12: Long-term efficiency potential in the utilization of electricity in the domestic and tertiary sector (D\&T) in \% efficiency increase. E13: When will half of this (E12) potential be realized under the assumption of constant energy prices? E17: Annual growth rate of electricity prices in the domestic and tertiary sector (D\&T) in \%, taking the price level at the beginning of the simulation as $100 \%$. E19: Long-term efficiency potential in the supply of electricity in \% efficiency increase. E20: When will half of this potential be realized under the assumption of constant energy prices? U201: Average annual change rate of the useful life of an average mass unit of ICT in \%. Secondary use is included in the useful life. W31: Longterm potential for recycling municipal solid waste (MSW), in \% of MSW. W32: When will half of this potential be realized? In years after the beginning of the simulation. G50: Economic elasticity of industrial materials demand with regard to materials prices for industrial customers. E220: Economic elasticity of industrial energy demand with regard to energy prices for industrial customers. E15: Economic elasticity of electricity demand with regard to electricity price in the domestic and tertiary sector. T97: Economic elasticity of air traffic demand with regard to air fares. T305: Economic elasticity of freight transport demand with regard to energy prices. 


\section{Creating a New Scenario Based on Empirical Data}

As seen in Section 4, none of three original scenarios A, B, or C emerges as a winner from the ex-post comparison to real-world data over the past 12 years. Therefore it is not a feasible plan to use today's knowledge to select the best among them to reduce the uncertainty of the simulation results. Instead, we will define a new scenario based on the empirical data available today, called "Scenario D", and re-run the model for this scenario.

The new Scenario D is directly based on empirical data: For the years 2000-2012, statistical time series were used (see the background report [27]), and for 2013-2020, the CAGR values drawn from this data (also shown in Table 1) were used for trend extrapolation. Figure 1 shows the role of Scenario D in the current study.

Re-running the model with these data will produce new output data for the entire simulation period 2000-2020. We expect this output to be different from the output the model produced when it was first run in 2003 under the assumption of scenarios $\mathrm{A}, \mathrm{B}$, or $\mathrm{C}$. The new simulation output will give us the following opportunities:

1. To validate the model by comparing the simulated trends with statistical data for the period 2000-2012. These trends are output data (such as "total energy consumption") and therefore not included in the scenario assumptions, but predicted by the model. These predictions can potentially be falsified and are therefore useful for model validation.

2. To compare the simulation results for 2020 (based on Scenario D) with the original results that were based on scenarios $\mathrm{A}, \mathrm{B}$, or $\mathrm{C}$ due to a lack of knowledge. Given that roughly half of the simulation period has passed since the model was first applied, we can expect to reduce the uncertainty when making predictions for the second half. In particular, it will be interesting if the quantitative results and qualitative conclusions of the study are still valid in light of the new and more realistic scenario D.

\section{Comparing Simulated Trends with Empirical Data}

This Section addresses the following research question, based on a search in currently available data:

RQ2: Are the main trends (in energy, transport, etc., as shown in Figures 6-2, 6-3, 6$4,6-5,6-6,6-7,6-8$, and 6-9 in [4]) that the IPTS model predicts for a realistic scenario consistent with the currently available data?

As mentioned earlier, none of the three scenarios dominantly represents the reality over the past years. So we defined a new scenario (Scenario D) based on the empirical data available today. Figures 2-4 show selected trends in energy, transport, and waste, comparing the simulated development in Scenario D with the real world trends. 
As shown in Figures 2-4, the predictions were roughly plausible, but cannot be taken as precise predictions, which is not surprising because the purpose of the model was not to predict the development of transport and energy demand and other environmental indicators in absolute terms, but the relative impact of ICT on these indicators. Further comparisons of the trends are presented in the background report [27].

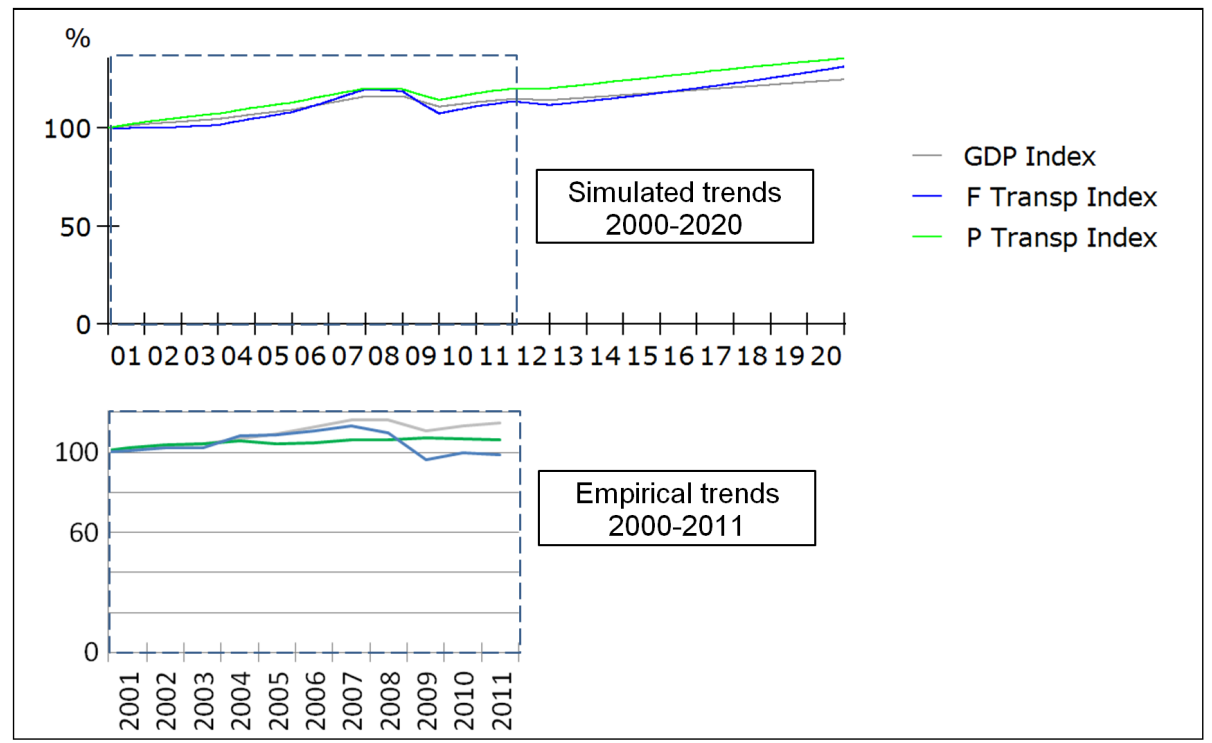

Fig. 2. Comparison of simulated trends (Scenario D, mean sub-scenario) with empirical trends [29] of: freight transport performance ("F Transp Index") and passenger transport performance ("P Transp Index"), compared to GDP index. $(2000=100 \%)$ 


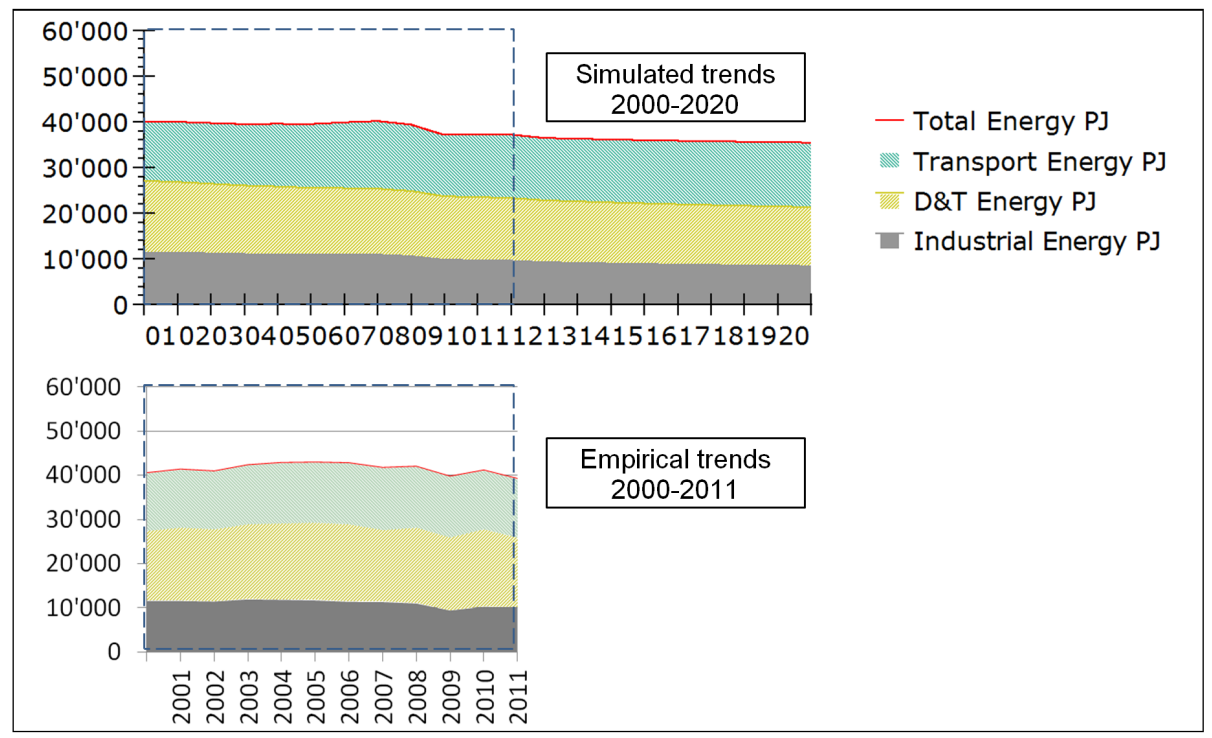

Fig. 3. Comparison of simulated trends (Scenario D) with empirical trends [43] of: energy consumption by the sectors transport, domestic and tertiary, and industry. Abbreviations: PJ: Petajoule; D\&T: Domestic and tertiary sector.

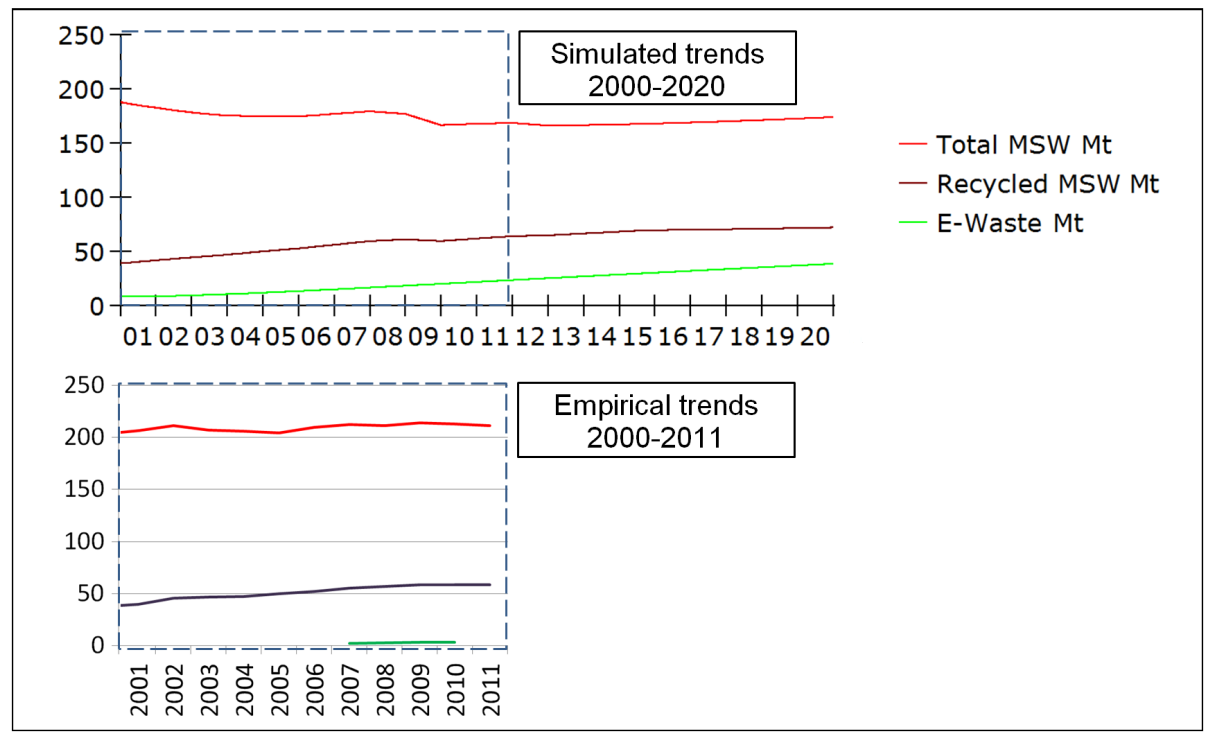

Fig. 4. Comparison of simulated trends (Scenario D) with empirical trends [44, 45] of: municipal solid waste (MSW), the recycling rate, and the e-waste fraction in megatonnes (Mt). 


\section{$7 \quad$ Reducing the Uncertainty of Simulation Results for 2020}

This section addresses the following research question, based on a search in currently available data:

RQ3: Can the main quantitative and qualitative results regarding the impact of ICT provided by the IPTS study be confirmed or disconfirmed and their uncertainty reduced by the currently available data?

The goal of the original model was to quantify the effect of ICT on environmental indicators in 2020. In order to do so, the model was applied according to the following steps:

1. Define the data for the external (i.e., independent) variables in the form of a scenario. We described this in Sections 3 to 5.

2. Create two versions of the given scenario, one which simulates the development of ICT as it is predicted over the simulation period (called "reference" run) and one which "freezes" ICT diffusion and use at the level of the year 2000 (called "ICT freeze"). An "ICT freeze" switch is built into the model for that purpose.

3. Calculate the difference between the reference and the "ICT freeze" version of the scenario.

4. Conduct sensitivity analyses with regard to all uncertain input that is not determined by the scenario. This yields three values for each result, one calculated under "best case," one under "worst case," and one under "mean" assumptions regarding all uncertain input that is not determined by the scenario. Total energy consumption is used as the lead output indicator that is minimized for the best case and maximized for the worst case.

5. Draw quantitative conclusions (with quantified uncertainties) and qualitative conclusions. For the original three scenarios A, B, and C, these conclusions were described mainly in [6] and [7], with background information in [4].

To answer RQ3, we first reproduce the steps 2 to 4 for Scenario D exactly as they were conducted for $\mathrm{A}$ to $\mathrm{C}$ in the original study.

\subsection{Simulation Results for Scenario D}

Table 2 presents the simulation results for the environmental indicators in 2020 in terms of a relative increase or decrease compared to their values in the year 2000 . The first row for each indicator shows the results of the simulation for our projected development of ICT (the reference run). The second row (the value in parentheses) shows the result for the "ICT freeze" version of the scenario, e.g., under the assumption that ICT remained as it was in 2000 . 
Table 2. Simulated values for environmental indicators in the year 2020, expressed in $\%$ of the values of the year 2000. Under the values of the reference run in each cell, the values in parentheses show the results for the "ICT freeze" simulation runs. The three columns represent the results calculated under worst-, mean, or best-case assumptions for uncertain model parameters. RES $=$ Renewable Energy Sources, $\mathrm{GHG}=$ GreenHouse Gas.

\begin{tabular}{lllll}
\hline \% & $\begin{array}{l}\text { Initial } \\
\mathbf{2 0 0 0}\end{array}$ & $\begin{array}{l}\text { D worst } \\
\mathbf{2 0 2 0}\end{array}$ & $\begin{array}{l}\text { D mean } \\
\mathbf{2 0 2 0}\end{array}$ & $\begin{array}{l}\text { D best } \\
\mathbf{2 0 2 0}\end{array}$ \\
\hline Total Freight Transport & 100 & 143 & 131 & 106 \\
& & $(145)$ & $(138)$ & $(130)$ \\
Total Passenger Transport & 100 & 140 & 136 & 130 \\
& & $(135)$ & $(129)$ & $(124)$ \\
Private Car Transport & 100 & 134 & 125 & 118 \\
& & $(142)$ & $(229)$ & $(121)$ \\
Total Energy Consumption & 100 & 97 & 89 & 77 \\
& & $(103)$ & $(98)$ & $(94)$ \\
RES Share in Electricity & 100 & 286 & 167 & 191.0 \\
& & $(141)$ & $(160)$ & $(179)$ \\
Total GHG Emissions & 100 & 78 & 79 & 64 \\
& & $(97)$ & $(89)$ & $(81)$ \\
Total Material Demand & \multirow{2}{*}{100} & 86 & 78.9 & 64 \\
& & $(101)$ & $(96)$ & $(90)$ \\
\hline
\end{tabular}

\subsection{Revisiting the Main Quantitative Results of the IPTS Study}

The ability to focus on Scenario D has reduced the span between the maximum and minimum values that were produced in the original study by running the model for all three scenarios as well as for a best-case, a mean, and a worst-case sub-scenario in each case. For example, the values for total freight transport, as shown Table 2, range from $106 \%$ in "D best" to $143 \%$ in "D worst" (i.e., a factor of 1.4 ), whereas, in the original study, this ranged from $85 \%$ in "B best" to $269 \%$ in "C worst" (a factor of 3.2) [4].

The role of ICT can be assessed by comparing the figures of the reference simulation run in each cell of Table 2 with the values in parentheses ("ICT freeze" run). Dividing the reference value by the corresponding "ICT freeze" value yields an index for the impact of ICT. Table 3 presents this index for all sub-scenarios for both the original scenarios $\mathrm{A}, \mathrm{B}$, and $\mathrm{C}$ and the new scenario $\mathrm{D}$. 
Table 3. ICT impact index (the value for the reference simulation run divided by the value for the corresponding "ICT freeze" run) for the five main output variables of the model used as environmental indicators. The values for Scenarios A-C are copied from [4], the values for Scenario D are newly computed. A value of 1.0 means that ICT has no influence, values $>1$ mean that ICT causes an increase of the environmental indicator by this factor, i.e., that ICT causes more environmental burden. Values $<1$ (emphasized by a gray background) indicate that ICT reduces environmental burden.

\begin{tabular}{lcccccccccccc}
\hline $\begin{array}{l}\text { ICT impact } \\
\text { index }\end{array}$ & $\begin{array}{c}\mathrm{A} \\
\text { worst }\end{array}$ & $\begin{array}{c}\mathrm{A} \\
\text { mean }\end{array}$ & $\begin{array}{c}\mathrm{A} \\
\text { best }\end{array}$ & $\begin{array}{c}\mathrm{B} \\
\text { worst }\end{array}$ & $\begin{array}{c}\mathrm{B} \\
\text { mean }\end{array}$ & $\begin{array}{c}\mathrm{B} \\
\text { best }\end{array}$ & $\begin{array}{c}\mathrm{C} \\
\text { worst }\end{array}$ & $\begin{array}{c}\mathrm{C} \\
\text { mean }\end{array}$ & $\begin{array}{c}\mathrm{C} \\
\text { best }\end{array}$ & $\begin{array}{c}\text { D } \\
\text { worst }\end{array}$ & $\begin{array}{c}\text { D } \\
\text { mean }\end{array}$ & $\begin{array}{c}\text { D } \\
\text { best }\end{array}$ \\
\hline $\begin{array}{l}\text { Freight } \\
\text { Transport }\end{array}$ & 1.04 & 1.01 & 0.90 & 1.32 & 1.27 & 1.11 & 1.03 & 0.98 & 0.83 & $\mathbf{0 . 9 9}$ & $\mathbf{0 . 9 5}$ & $\mathbf{0 . 8 1}$ \\
$\begin{array}{l}\text { Passenger } \\
\text { Transport }\end{array}$ & 1.03 & 1.02 & 1.01 & 1.04 & 1.04 & 1.02 & 1.03 & 1.02 & 1.00 & $\mathbf{1 . 0 3}$ & $\mathbf{1 . 0 5}$ & $\mathbf{1 . 0 4}$ \\
Energy & 0.98 & 0.95 & 0.89 & 1.03 & 0.99 & 0.92 & 0.97 & 0.93 & 0.85 & $\mathbf{0 . 9 4}$ & $\mathbf{0 . 9 0}$ & $\mathbf{0 . 8 2}$ \\
GHG & 0.97 & 0.93 & 0.87 & 1.03 & 0.98 & 0.90 & 0.97 & 0.92 & 0.83 & $\mathbf{0 . 8 1}$ & $\mathbf{0 . 8 9}$ & $\mathbf{0 . 7 9}$ \\
Materials & 0.90 & 0.88 & 0.79 & 1.00 & 0.97 & 0.87 & 0.90 & 0.86 & 0.74 & $\mathbf{0 . 8 5}$ & $\mathbf{0 . 8 3}$ & $\mathbf{0 . 7 1}$ \\
\hline
\end{tabular}

Similar to the pattern seen for the original scenarios, the impact of ICT in the new Scenario D seems to be basically stimulating for passenger transport and basically inhibiting for energy, GHG, and materials. However, for freight transport, the new scenario shows a slightly inhibiting effect of ICT (0.99) even under worst-case assumptions (see below for explanation).

A general observation is that the impact of ICT on the environmental indicators is roughly between $-25 \%$ and $+30 \%$ in the original scenarios and roughly between $-30 \%$ and $+5 \%$ in Scenario D (rounded extreme values from Table 3). Scenario D, which is based on empirical data, seems to have changed the behavior of the model in the following way: the potential damage caused by ICT is reduced, but not the potential positive effect, which even seems to be slightly higher. This can be explained by the fact that energy prices have been increasing faster since 2000 than assumed in all scenarios of the original study. Higher energy prices work against rebound effects.

In any case, the overall conclusion of the original study that "the impact of ICT on the environmental indicators is relevant and should be taken into account by environmental policies" [4] is still valid. It should also be repeated that ICT can have positive and negative environmental effects in different areas and that policy-makers should strive to systematically support the positive (decreasing) effects and inhibit the negative ones. The effects in the three main areas freight transport, passenger transport, and energy are discussed in more detail below.

Freight Transport. As shown in Table 3, ICT has a reducing influence on total freight transport demand (which is different from the pattern of increasing effects in the original scenarios). With the "ICT freeze," as shown in Table 2, we have roughly the same level of increase in "D worst" that we see with the reference run, i.e., about 
$45 \%$ increase in both runs. In "D mean" we have about $7 \%$ more increase in freight transport for "ICT freeze," which could still be considered insignificant given the overall uncertainty of the results. In "D best," however, we have the difference of roughly $25 \%$ more freight transport with "ICT freeze." This means that - under the most optimistic assumptions made with regard to all uncertain model parameters there could be less increase in freight transport by roughly $25 \%$ due to ICT. This effect is then mainly due to the virtualization of goods (which is seen in Table 2 and 3 as the reducing influence of ICT on total material demand), leading to less transport demand, and to a much lesser extent due to the optimization effect of ICT, which makes transport cheaper and therefore leads to a rebound effect. One could conclude that, if the model is correct, a policy intending to reduce freight transport should focus more on the dematerialization of goods than on the optimization of logistics.

Passenger Transport. As shown in Table 3, ICT also has an increasing influence on total passenger transport in Scenario D. As shown in Table 2, the simulated values in Scenario D show an increase in passenger transport in 2020 for both reference and "ICT freeze" runs, even though the increase with the "ICT Freeze" is slower. So there is a larger increase in the reference run, which is explained by the fact that ICT generates demand for passenger transport by making passenger transport more time efficient. This basic effect is still observed in the new scenario; the picture changes if we differentiate between modes of transport (see the background report [27] for detailed results on passenger transport modes). As shown in Table 2, ICT seems to help slow the growth in private car transport. This can be explained by the time utilization effect represented in the model: Mobile ICT makes it possible to use the time spent on public transport more productively. The extent of this effect with regard to the comparative disadvantage it produces for private car transport is even greater in Scenario D than it was in the original scenarios.

Total Energy Demand. In the new results, ICT has decreasing impact on total energy consumption, not only confirming the decreasing pattern in the original results, but also demonstrating a more optimistic perspective (e.g., see the lower "best" and "mean" values in Scenario D compared to the corresponding values in the original scenarios). Intelligent heating is an area where ICT can help reduce energy consumption. Taking the energy consumption in the domestic and tertiary sector (one of the main components of total energy consumption in the model) as a proxy for heating energy consumption, the simulated values in the new scenario D for the year 2020, expressed in percentages (assuming 100\% for the year 2000) are as follows: 87 (92) for "D worst," 82 (94) for "D mean," and 81 (95) for "D best" [27] - the values in parentheses again indicate "ICT freeze" results. Although the efficiency of heating and other energy consumption in buildings is increasing even with ICT "frozen" at the level of 2000, ICT has a boosting effect on this efficiency. Using Scenario D assumptions, ICT is responsible for saving $15 \%$ of the energy consumed in the domestic and tertiary sector, mainly due to intelligent heating (which is not presented here, but is 
the main effect behind these figures in the model). This result of the original study is therefore confirmed and even reinforced by the simulation output of Scenario D.

\subsection{Revisiting the Main Qualitative Results of the IPTS Study}

Table 4 presents the main qualitative results (main conclusions) of the original IPTS study [9] and briefly evaluates them in light of the new simulation results based on Scenario D.

Table 4. Revisiting the main conclusions of the IPTS study (cited from [9]) by checking them against the new results produced for this book chapter

\begin{tabular}{l} 
Main conclusions of the original IPTS study [9] \\
\hline ICT applications supporting a product-to-service shift (virtual \\
goods) \\
"Although there are widely diverging opinions concerning an ICT- \\
supported product-to-service shift and its potential energy saving and \\
dematerialization effects until 2020, it is the high potential for change \\
that makes this issue important. In the model, almost every output \\
turned out to be directly or indirectly linked to the product-to-service \\
shift variables, first of all freight transport, but also waste and the ener- \\
gy used by the industrial sector."
\end{tabular}

ICT applications for heating management (intelligent heating)

"ICT has a high potential impact on the rational use of heating energy. Heating accounts for roughly $30 \%$ of total energy consumption and conservation measures using physical materials tend only to be applied to the small annual share of buildings that is renovated or newly built. 'Soft measures' using ICT (such as intelligent heating systems) have the advantage of being applicable in all buildings, and could therefore have a significant effect."

\section{ICT applications for passenger transport efficiency}

"All ICT applications that make passenger transport more time efficient (such as ITSs) will create a rebound effect leading to more traffic and possibly more energy consumption. Induced passenger transport demand has severe environmental consequences in energy use and greenhouse gas emissions, although ICT contributes to lowering the energy and GHG intensity of passenger transport."

\section{ICT applications for mobile work}

"Mobile work enabled or supported by pervasive computing and other new forms of ICT application can have a significant effect on passenger transport, because it increases the share of time spent in traffic that people can use productively. This can create more transport demand, while stimulating public transport more than private car transport. The effects of ICT on personal time management and time utilization are probably the most underestimated indirect impacts of ICT on the environment, with great potential in either direction."

\section{ICT applications for freight transport efficiency}

"All ICT applications that make freight transport more cost efficient (i.e. cheaper) will immediately create more freight transport and more energy consumption. There is no evidence for assuming anything other than a strong price rebound effect here. By making transport more cost efficient, ICT creates freight transport demand, with severe environmental effects, unless measures are taken to limit demand of transport."

\section{The main conclusions} revisited

Confirmed by new results. ICT has a reducing influence on total material demand (dematerialization effect).

Confirmed by new results. ICT has reducing effect on energy consumption in the domestic and tertiary sector, which is dominated by heating.

Confirmed by new results. ICT has a stimulating influence on total passenger transport by making it more cost and time efficient (rebound effect).

Confirmed by new results. Time utilization effects of mobile ICT create an advantage for public transport compared to private car transport.

Not confirmed by new results. ICT now slightly inhibits growth of freight transport. This ICT effect is mainly due to its dematerialization effect, which is stronger than in the original study. 


\section{Conclusions and Future Research}

Revisiting the IPTS study on future impact of ICT on environmental sustainability in EU-15 for the time horizon of 2020, we answered three questions on the inputs and outputs of the model and the main conclusions of the IPTS study:

Which of the three scenarios in the IPTS study comes closest to reality? (RQ1) In response to this question we collected empirical data and found that none of the scenarios can be considered realistic. Based on the data, we defined a new scenario which was then used for further simulation experiments.

Are the main trends the IPTS model predicts for a realistic scenario consistent with the currently available data? (RQ2) Simulation runs based on the new scenario were compared with empirical trends for selected categories such as transport and energy. The predictions were roughly plausible, but cannot be taken as precise predictions, which is not surprising because the purpose of the model was not to predict the development of transport and energy demand and other environmental indicators in absolute terms, but the relative impact of ICT on these indicators.

Can the main quantitative and qualitative results regarding the impact of ICT provided by the IPTS study be confirmed or disconfirmed and their uncertainty reduced by the currently available data? (RQ3) In response to this question we found the following results.

The results of the IPTS study indicate that ICT will slow the growth of private car transport, but will stimulate the growth of total passenger transport. This and the other main results of the original study were confirmed, with the exception of the impact of ICT on freight transport, which was now more environmentally positive (leading to a bit less growth of freight transport) due to the stronger dematerializing effect of ICT. Overall, it seems that Scenario D has made the simulation results slightly more positive (optimistic) with regard to the effect of ICT on the environmental indicators, compared to the old results. The availability of empirical data which made it possible to define Scenario D reduced the error margins of the input data (difference between the best- and worst-case assumptions for uncertain parameters), which also reduced the uncertainty of some output variables, but not of all of them. The span between the best- and worst-case results for 2020 could be reduced for all environmental indicators (expressed in \% of the year 2000 initial value of each indicator): From $180 \%$ to below $40 \%$ for total freight transport, from $40 \%$ to $10 \%$ for total passenger transport, from $50 \%$ t $20 \%$ for energy consumption, from $60 \%$ to $15 \%$ for GHG emissions, and from $60 \%$ to $20 \%$ for total material demand [27].

The IPTS study used many socioeconomic input and output variables. In this revisiting effort, we collected empirical data from statistical sources such as EuroStat. EuroStat regularly prepares statistics on the information society, tracking the usage of ICT. However, many ICT-relevant parameters used in the study (e.g., average telework hours and average lifetime of ICT devices in the EU) were not covered by EuroStat, and it was difficult to find empirical data on the trends of such parameters. Future work could provide detailed data requirements for systematic and comprehensive tracking of development and usage of ICT. 
The feedback-loop mechanisms used in the IPTS model enabled it to take the rebound effects of ICT applications into account. For example, two types of rebound effect in passenger transport, one based on increased cost efficiency (direct economic rebound) and one based on increased speed (time rebound) were modeled to explore the role of ICT in passenger transport demand. A further step would be to equip the model with an economic framework to conduct a quantitative analysis of the magnitude of rebound effects. Such economic frameworks have already been presented in previous studies, e.g., [31], which evaluated energy efficiency rebound, showing that it likely reduced the net savings by roughly $10 \%$ to $40 \%$ in two cases of energy efficiency improvements.

The IPTS study employed System Dynamics, a macro-level approach to modeling the causal mechanisms underlying socioeconomic systems. Other modeling approaches such as agent-based modeling with a focus on micro-level aspects and dynamic interactions of individual actors and institutions can be employed to provide a complementary perspective on how ICT affects environmental sustainability and to explore how changes at the micro level aggregate to macro-level effects.

\section{Acknowledgments}

The authors would like to thank Empa, KTH (Center for Sustainable Communications), and Vinnova, which made this work possible as a part of the first author's $\mathrm{PhD}$ project.

\section{References}

1. Erdmann, L., Würtenberger, F.: The future impact ICT on environmental sustainability. First Interim Report. Identification and global description of economic sectors. Institute for Prospective Technology Studies (IPTS), Sevilla (2003)

2. Erdmann, L., Behrendt, S.: The future impact ICT on environmental sustainability. Second Interim Report. Institute for Prospective Technology Studies (IPTS), Sevilla (2003)

3. Goodman, J., Alakeson, V.: The future impact ICT on environmental sustainability. Third Interim Report. Scenarios. Institute for Prospective Technology Studies (IPTS), Sevilla (2003)

4. Hilty, L.M., Wäger, P., Lehmann, M., Hischier, R., Ruddy, T.F., Binswanger, M.: The future impact of ICT on environmental sustainability. Fourth Interim Report. Refinement and quantification. Institute for Prospective Technological Studies (IPTS), Sevilla (2004)

5. Arnfalk, P.: The future impact ICT on environmental sustainability. Fifth Interim Report. Evaluation and Recommendations. Institute for Prospective Technology Studies (IPTS), Sevilla (2004)

6. Erdmann, L., Hilty, L.M., Goodman, J., Arnfalk, P.: The future impact ICT on environmental sustainability. Synthesis Report. Institute for Prospective Technology Studies (IPTS), Sevilla (2004)

7. Arnfalk, P., Erdmann, L., Goodman, J., Hilty, L.M.: The future impact of ICT on environmental sustainability. In: Proceedings EU-US Scientific Seminar on New Technology Foresight, Forecasting \& Assessment Methods, 13-14 May 2004, Seville, Spain (2004) 
8. Wäger, P., Hilty, L. M., Arnfalk, P., Erdmann, L., Goodman, J.: Experience with a System Dynamics model in a prospective study on the future impact of ICT on environmental sustainability. In: Voinov, A., Jakeman, A.J., Rizzoli, A.E. (eds.) Proceedings of the iEMSs Third Biennial Meeting, Summit on Environmental Modelling and Software. International Environmental Modelling and Software Society, Burlington, USA (2006)

9. Hilty, L.M., Arnfalk, P., Erdmann, L., Goodman, J., Lehmann, M., Wäger, P.: The Relevance of Information and Communication Technologies for Environmental Sustainability - A Prospective Simulation Study. Environ. Modell. Softw. 11 (21), 1618-1629 (2006)

10. Erdmann, L., Hilty, L.M.: Scenario Analysis: Exploring the Macroeconomic Impacts of Information and Communication Technologies on Greenhouse Gas Emissions. J. Ind. Ecol. 14 (5), 826-843 (2010)

11. Ruddy, T.F., Hilty, L.M.: Impact Assessment and Policy Learning in the European Commission. Environ. Impact Assess. Rev. 28 (2-3), 90-115 (2008)

12. Kelly (Letcher), R.A., Jakeman, A.J., Barreteau, O., Borsuk, M.E., ElSawah, S., Hamilton, SH., Henriksen, H.J., Kuikka, S., Maier, H.R., Rizzoli, A.E., Van Delden, H., Voinov, A.A.: Selecting among five common modelling approaches for integrated environmental assessment and management. Environ. Modell. Softw. 47, 159-181 (2013)

13. European Commission: Annual Report on European SMEs (2013)

http://ec.europa.eu/enterprise/policies/sme/facts-figures-analysis/performancereview/index_en.htm (2013)

14. The European Environment Agency: Efficiency of conventional thermal electricity and heat production (2012), http://www.eea.europa.eu/data-and-maps/figures/efficiency-ofconventional-thermal-electricity-4

15. The European Environment Agency: Odyssee energy efficiency index (ODEX) for EU-27 (2012), http://www.eea.europa.eu/data-and-maps/indicators/energy-efficiency-and-energyconsumption-5/assessment

16. Eurostat: GDP and main components - volumes. Product code: nama_gdp_k (2014)

17. Eurostat: Employment (main characteristics and rates) - annual averages. Product code: lfsi_emp_a (2014)

18. Eurostat: Demographic balance and crude rates. Product code: demo_gind (2014)

19. Eurostat: Number of private households by household composition, number of children and age of youngest child (1 000). Product code: lfst_hhnhtych (2014)

20. Eurostat: Electricity prices for household consumers (2014), http://epp.eurostat.ec.europa.eu/tgm/table.do?tab=table\&init=1\&language=en\&pcode=ten 00115 \&plugin $=1$

21. Eurostat: Annual enterprise statistics for special aggregates of activities (NACE Rev. 2). Product code: sbs_na_sca_r2 (2014)

22. Finnish Environment Institute: Average commuting distance (2012), http://www.findikaattori.fi/en/70

23. Greene, D.L., Tishchishyna, N.I.: Costs of Oil Dependence: A 2000 Update. Oak Ridge National Laboratory, ORNL/TM-2000/152, Oak Ridge, TN, 2000, and data updates (2012), http://cta.ornl.gov

24. US EPA: Report to Congress on Server and Data Center Energy Efficiency, Public Law 109-431. Prepared for the U.S. Environmental Protection Agency, ENERGY STAR Program, by Lawrence Berkeley National Laboratory. LBNL-363E (2007)

25. Babbitt, C.W., Kahhat, R., Williams E.: Evolution of product lifespan and implications for environmental assessment and management: a case study of personal computers in higher education. Environ. Sci. Technol. 43, 5106-5112 (2009) 
26. Robinson, B.H.: E-waste: an assessment of global production and environmental impacts. Sci. Total Environ. 408.2, 183-191 (2009)

27. Achachlouei, M.A., Hilty, L.: Simulating the Future Impact of ICT on Environmental Sustainability: Validating and Re-calibrating a System Dynamics Model. Technical report, CESC Centre for Sustainable Communications (in preparation)

28. Eurostat: Generation and treatment of municipal waste $(1000 \mathrm{t})$ by NUTS 2 regions. Product code: env_rwas_gen (2014)

29. European Commission: Statistical pocketbook 2013, http://ec.europa.eu/transport/factsfundings/statistics/pocketbook-2013_en.htm

30. European Parliament: The Impact of the Oil Price on EU Energy Prices (2014), http://www.europarl.europa.eu/RegData/etudes/etudes/join/2014/518747/IPOLITRE_ET(2014)518747_EN.pdf

31. Borenstein, S.: A microeconomic framework for evaluating energy efficiency rebound and some implications. No. WP 242R. National Bureau of Economic Research (2014)

32. Saunders, W.: Server Efficiency: Aligning Energy Use with Workloads. Data Center Knowledge (2012), http://www.datacenterknowledge.com/archives/2012/06/12/serverefficiency-aligning-energy-use-with-workloads

33. Green500: The Green500 List - November 2013: The Green500's energy-efficient supercomputers, http://www.green500.org/lists/green201311

34. Belady, C., Rawson, A., Pfleuger, J.O.H.N., Cader, T.A.H.I.R.: The Green Grid Data Center Power Efficiency Metrics: PUE and DCiE. Technical report, Green Grid (2008)

35. The Uptime Institute: Data Center Industry Survey (2013), www.datacentral.org/resource/collection/BC649AE0-4223-4EDE-92C7-29A659EF0900/uptimeinstitute-2013-data-center-survey.pdf

36. Coroama, V.C., Hilty, L.M.: Assessing Internet energy intensity: A review of methods and results. Environ. Impact Assess. Rev. 45, 63-68 (2014)

37. Mannaerts, H.: Environmental policy analysis with STREAM: a partial equilibrium model for material flows in the economy. In: van den Bergh, J.C.J.M., Janssen, M. (eds.) Economics of Industrial Ecology: Materials, Structural Change, and Spatial Scales, pp. 195222. Massachusetts Institute of Technology (2004)

38. Smyth, M., Pearce, B.: IATA Economics N ${ }^{\circ}$ : Air Travel Demand (2008), http://www.iata.org/whatwedo/Documents/economics/air_travel_demand.pdf

39. de Jong, G., Schroten, A., Van Essen, H., Otten, M., Bucci, P.: Price sensitivity of European road freight transport-towards a better understanding of existing results. A report for Transport and Environment. 9012-1 (2010)

40. Borenstein, S.: To what electricity price do consumers respond? Residential demand elasticity under increasing-block pricing. Preliminary Draft (2009), http://faculty.haas.berkeley.edu/borenste/download/NBER_SI_2009.pdf

41. Börjeson, L., Höjer, M., Dreborg, K.H., Ekvall, T., Finnveden, G.: Scenario types and techniques: towards a user's guide. Futures, 38(7), 723-739 (2006)

42. European Commission: World Energy, Technology and Climate Policy Outlook. EC Research DG (2002)

43. Eurostat: Supply, transformation, consumption - all products - annual data. Product code: nrg_100a (2013)

44. Eurostat: EuroStat: Municipal waste. Product code: env_wasmun (2014)

45. Eurostat: Waste Electrical and Electronic Equipment (WEEE). Product code: env_waselee (2014)

46. Taylor C., Koomey J.: Estimating Energy Use and Greenhouse Gas Emissions of Internet Advertising. IMC2 (2008) 